\title{
A Survey on Relay Selection in Cooperative Device-to-Device (D2D) Communication in 5G Cellular Networks
}

\author{
K.Shamganth ${ }^{\mathrm{a}}$, Said Shafi Abdullah Al-Shabibi ${ }^{\mathrm{a}}$
}

\begin{abstract}
Device-to-device (D2D) communications underlayed to a cellular infrastructure has recently been proposed to increase spectrum and energy efficiency. Relay selection plays a vital role in cooperative networks. In D2D communication, if the chosen relay is not the best relay, then the whole communication will not be successful from source node to destination node. Also to choose the optimal relays, if more feedback and time delay exists between the source nodes and relay node then it leads to degradation of spectral efficiency. A survey on the relay selection techniques used with D2D communications and the challenges and design issues associated with the integration of D2D in $5 \mathrm{G}$ cellular network is presented.
\end{abstract}

Keywords: cooperative communication; device-to-device communication; relay selection; 5G cellular networks

\section{Introduction}

Device-to-Device (D2D) communication is considered as a promising technique in 5G cellular network technologies. D2D communication in cellular network refers to the direct communication between the mobile users without the involvement of Base Station (BS) or the core network elements. In 3G network D2D communication is used in unlicensed band using Bluetooth and WLAN. Cellular networks are categorized into two types Network centric and Device centric [1]. Network centric means communication between mobile users depends on the network infrastructure and is mainly used in $1 \mathrm{G}$ to $4 \mathrm{G}$ networks. Device centric means network setup is managed by the proximate device itself and it will be considered as the core technology in 5G cellular network.

D2D in cellular network has the following expectations:

- Enhanced system capacity

- Increased spectral efficiency

- Better throughput

- Reduced Latency

D2D reduces load at the base station since it does not involve base station intervention for communication between devices, so the load at the base station is drastically reduced. This in turn reduces the power required by the base station. The concept of D2D and MANET seems to be same from the outset but detailed investigation will provide the differences between MANET and D2D as shown in Table I.

Scope of the paper: In this paper, we will review the cooperative D2D communication scenarios, types of relay selection techniques can be applied to D2D communication in $5 \mathrm{G}$ cellular networks. Section II will elaborate the categories of D2D communication scenarios. In Section III presents the benefits of two-tier cellular network compared with conventional cellular network. Section IV presents the survey of proposed relay selection techniques that suits for D2D communication in 5G cellular network. Section V addresses the research challenges of integrating D2D communication in $5 \mathrm{G}$ cellular networks.

Table 1: Differences between MANET and D2D

\begin{tabular}{|l|l|l|}
\hline Parameters & \multicolumn{1}{|c|}{ MANET } & \multicolumn{1}{|c|}{ D2D } \\
\hline QoS & $\begin{array}{l}\text { No QoS } \\
\text { guarantees }\end{array}$ & QoS Guaranteed \\
\hline $\begin{array}{l}\text { Centralized } \\
\text { Control }\end{array}$ & $\begin{array}{l}\text { No Centralized } \\
\text { control }\end{array}$ & $\begin{array}{l}\text { Control can exist from Base } \\
\text { station or from device itself } \\
\text { (Partial or Full Control }\end{array}$ \\
\hline $\begin{array}{l}\text { Resource } \\
\text { constraints }\end{array}$ & $\begin{array}{l}\text { Severe } \\
\text { resource } \\
\text { constraints } \\
\text { exist }\end{array}$ & Resource allocation exist \\
\hline $\begin{array}{l}\text { Number of } \\
\text { Hops }\end{array}$ & $\begin{array}{l}\text { Multi-hop } \\
\text { Network }\end{array}$ & Single-hop Network \\
\hline $\begin{array}{l}\text { Spectral } \\
\text { efficiency }\end{array}$ & $\begin{array}{l}\text { No } \\
\text { improvement } \\
\text { in Spectral } \\
\text { efficiency }\end{array}$ & $\begin{array}{l}\text { Improvement in Spectral } \\
\text { efficiency }\end{array}$ \\
\hline Security & Less Security & Highly Secured \\
\hline
\end{tabular}

\section{Categories of D2D communications in $5 \mathrm{G}$ networks}

D2D communication is classified into two types based on the spectrum [4] used for the communication as shown in Fig.1. D2D network may use the licensed spectrum and it known as Inband. And the D2D network using unlicensed spectrum for direct link establishment is Outband.

Inband D2D communication is categorized as Underlay and Overlay [6]. Underlay D2D communication allows the

a. Department of Engineering, Ibra college of technology, Ibra, Oman

Correspondence: shamkanth@ict.edu.om 
setup of direct links between devices and cellular links using the network infrastructure to use the cellular spectrum. In Overlay D2D communication a dedicated band is used for direct links between devices and the rest of the spectrum used for cellular communication.

Outband D2D communication use the unlicensed spectrum for establishing links between devices[5]. It can be controlled or autonomous. In Controlled D2D communication radio intefaces between $\mathrm{D} 2 \mathrm{D}$ links controlled by the base station. In Autonomous D2D communication devices will manage the radio interfaces for the network setup.

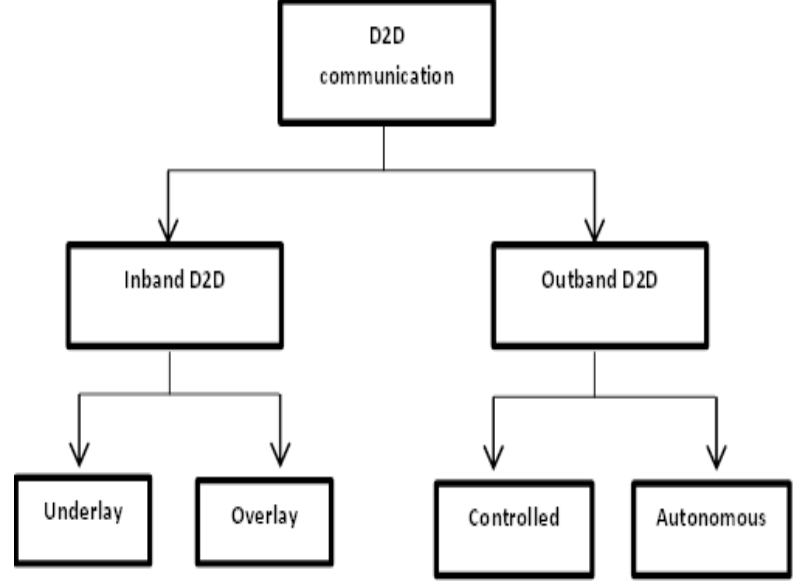

Fig.1: Types of Device to Device Communication [4]

Device Relaying with control exists from Base-station:

Scenarios such as poor coverage areas or at cell edges device can communicate with the base station through this method [2]. Base station has full control over the communication between the intended device and the relaying device and allocates the resources, so that the device near to the base station will act as a relay for the intended mobile device to communicate with the base station as shown in Fig. 2.

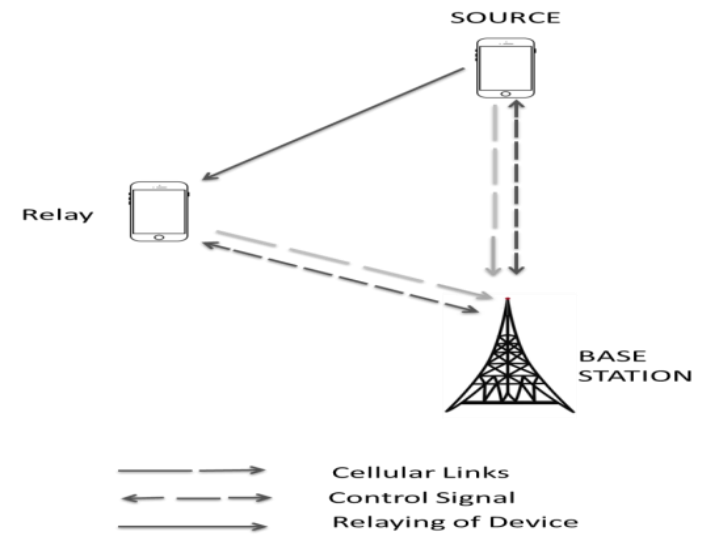

Fig.2: Relaying device with control link from Base station Direct communication between devices through base station

Two devices communicate effectively through the control from the base station as shown in Fig.3. Centralized control exists in this scenario which effectively performs interference management and resource allocation.

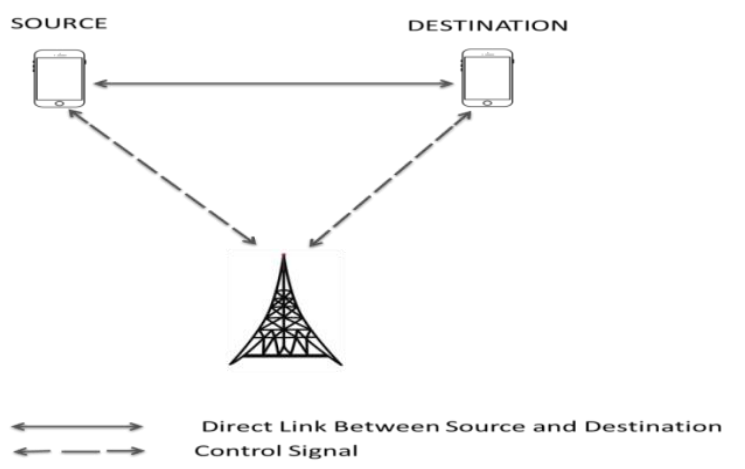

Fig.3: Direct communication between devices with control from base station

Device relaying with full control from the device

In this type base station is not controlling the D2D communication. Control is performed in a distributive fashion where the communication between source node and destination node is through a relay as shown in Fig.4. And the control in this scenario for example resource allocation, call set up and interference management will be performed by the device.

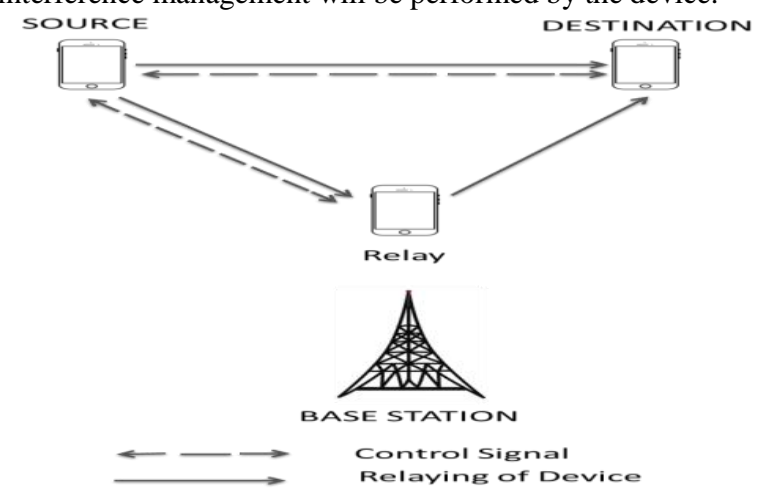

Fig.4: Device relaying with full control from device

Direct communication between devices without base station control

Devices communicate directly without the control from the base station as shown in Fig.5. So the call setup and interference management take care by the device itself.
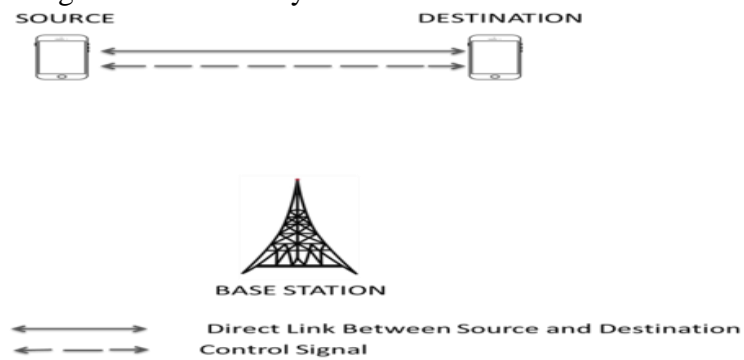

Fig.5: Direct communication between devices

Two Tier cellular networks Vs conventional cellular networks

Benefits of two-tier cellular network compared with conventional cellular network [1] are mentioned below:

\section{One-Hop communication}


Devices can communicate with each other through single -hop. So lesser resources are required like less spectrum usage also the latency is reduced.

TABle II. LTE Device-To-Device Proximity scenarios [3] Spectrum Reusability

Spectrum used by the cellular network users in network tier and the D2D users in the device tier can be same. This supports Spectrum reusability.

\section{Power-level Optimization}

D2D links exists between devices over a small distance so the transmission power is less. Higher energy efficiency can be achieved since it enhances the battery life of the device involved.

\section{Improved coverage area}

D2D Communication is possible with relays and it enhances the coverage ranges.

\section{Relay selection in Cooperative D2D communication for cellular networks}

Relay selection plays a vital role in cooperative networks. If the chosen relay is not the best relay then the whole communication will not take place from source node to destination node [7]. Table III shows the summary of proposed relay selection algorithms for Cooperative D2D communication.

Relay selection mechanisms categorized as follows:

\section{- Centralized Relay selection \\ - Distributed Relay selection}

\section{Centralized Relay Selection}

Systems with pre-defined infrastructure for example cellular networks, users communicate with a central base station. In this type of relay selection central base station collects and utilizes the required information to select one or more relays to each source-destination pair.

\section{Distributed Relay Selection}

Systems such as ad-hoc networks which do not have centralized control, in this category each node individually determines whether to cooperate and whom to cooperate with according to the information exchanged between nodes

\section{Challenges and Design issues of D2D communication in 5G Networks}

There are some technical challenges exists in the integration of D2D communication in cellular networks and it is considered to be the open area for research [14].

- Relay Selection

- Interference Management

- Peer discovery

- Resource allocation

\section{Relay Selection}

- Network Security

Relay Selection is the major issue in Cooperative D2D networks. It is a design goal to make this process efficient and optimized. In cellular network the relay selection can be centralized or distributed. The role of network in the relay selection is an important design question.

Interference Management
Smart Interference management scheme for D2D users for device tier need to be designed it gives wide range of research opportunities in this area. Also Interference cancellation in full-duplex radio network is still an open problem and to be explored.

\section{Peer Discovery}

The process of Peer discovery should be efficient so that D2D links are discovered and established quickly. It is also important for ensuring efficiency and resource allocation within the system and there is an open area for research.

\section{Resource allocation}

Radio resource allocation is important to enhance the spectral efficiency in D2D communication.

\section{Network Security}

When exchanging information through relays in D2D communication network security is the major concern and there exists an open area for research.

\begin{tabular}{|c|l|l|l|}
\hline Refere & \multicolumn{1}{|c|}{ Algorit } & $\begin{array}{l}|c| \\
\text { ion Obscript }\end{array}$ & \multicolumn{1}{|c|}{ Objecti } \\
ne
\end{tabular}




\begin{tabular}{|c|c|c|c|}
\hline & & $\begin{array}{l}\text { offload their } \\
\text { data to the } \\
\text { eNB via it. The } \\
\text { proposed } \\
\text { framework } \\
\text { optimally } \\
\text { selects } \\
\text { appropriate } \\
\text { transmission } \\
\text { mode and the } \\
\text { relay node. } \\
\text { Proposed } \\
\text { model is } \\
\text { robust enough } \\
\text { to handle the } \\
\text { variations of } \\
\text { the channel } \\
\text { and mobility } \\
\text { of the UEs, } \\
\text { appropriately } \\
\text { selects the } \\
\text { transmission } \\
\text { power, } \\
\text { modulation } \\
\text { scheme, and } \\
\text { rate of } \\
\text { transmission } \\
\text { of the UEs }\end{array}$ & $\begin{array}{l}\text { scheme is } \\
\text { proposed. }\end{array}$ \\
\hline [12] & \begin{tabular}{l}
\multicolumn{1}{c}{ Energy } \\
Efficient \\
Relay \\
Selection in \\
D2D network
\end{tabular} & $\begin{array}{l}\text { A D2D } \\
\text { network with } \\
\text { random } \\
\text { deployment of } \\
\text { relay nodes } \\
\text { between the } \\
\text { source and the } \\
\text { destination. } \\
\text { The relay } \\
\text { nodes are } \\
\text { grouped into } \\
\text { clusters, which } \\
\text { act } \\
\text { cooperatively } \\
\text { to enhance } \\
\text { network } \\
\text { reliability }\end{array}$ & $\begin{array}{l}\quad \text { Energy- } \\
\text { efficient relay } \\
\text { selection } \\
\text { schemes for } \\
\text { cooperative } \\
\text { multi-hop } \\
\text { device-to- } \\
\text { device (D2D) } \\
\text { networks is } \\
\text { studied. }\end{array}$ \\
\hline [13] & $\begin{array}{l}\text { Joint Relay } \\
\text { Selection and } \\
\text { Resource } \\
\text { allocation }\end{array}$ & $\begin{array}{l}\text { The selection } \\
\text { cooperation } \\
\text { (SC) rule } \\
\text { restricts } \\
\text { relaying for a } \\
\text { D2D } \\
\text { transmitter to } \\
\text { only one relay } \\
\text { (i.e., another } \\
\text { D2D } \\
\text { transmitter) is } \\
\text { imposed. The } \\
\text { resource } \\
\text { allocation } \\
\text { problem for } \\
\text { the } \\
\text { cooperative } \\
\text { D2D } \\
\text { transmitters is } \\
\text { studied using } \\
\text { game theory. }\end{array}$ & $\begin{array}{l}\text { An efficient } \\
\text { resource } \\
\text { allocation } \\
\text { scheme and a } \\
\text { low } \\
\text { complexity } \\
\text { relay } \\
\text { selection } \\
\text { strategy is } \\
\text { proposed for } \\
\text { D2D } \\
\text { communicati } \\
\text { ons enabled } \\
\text { cellular } \\
\text { networks, } \\
\text { where a D2D } \\
\text { UE can act as } \\
\text { a source as } \\
\text { well as a } \\
\text { potential } \\
\text { relay for } \\
\text { other UEs }\end{array}$ \\
\hline
\end{tabular}

TABLE III. SUMMARY OF PROPOSED RELAY SELECTION ALGORITHMS FOR COOPERATIVED2D COMMUNICATION

\section{Conclusion}

In this paper, an extensive survey on D2D communication is performed. A complete overview on the types of D2D communication and supported architectures is presented. Survey on relay selection algorithms in D2D communication for 5G cellular networks provided the problem and method used in the algorithm to solve the problem. Challenges and research directions in D2D communication for $5 \mathrm{G}$ cellular network is elaborated.

\section{ACKNOWLEDGMENT}

The author would thank Middle East College for all the valuable resources that was provided in order to complete this project. Special thanks to the kind guidance and support that was giving from the supervisor, Dr. Vrajesh Maheta, who provide real assistance and offered different valuable feedback on the project progress and work.

\section{References}

Li Wang and Huan Tang, Device-to-Device Communication in Cellular Networks. Springer, 2016.

Pimmy Gandotra, Rakesh Kumar Jha, "Device-to-Device Communication in Cellular Networks: A Survey," Journal of Network and Computer Applications, vol.71, pp.99-117, 2016.

Rohde \& Schwarz: White Paper 1MA232 "LTE-Advanced (3GPP Rel.12) Technology Introduction,” June 2014.

Arash Asadi, Qing Wang, and Vincenzo Mancuso, "A Survey on Device-to-Device Communication in Cellular Networks," IEEE Communiction Surveys \& Tutorials, vol. 16, No. 4, pp.18011819,2014

Ahmed S.ibrahim, "Cooperative Communications with RelaySelection: When to Cooperate and Whom to Cooperate With?," IEEE Trans.Wireless Commn.vol.7.No.7, pp.2814-2827,July 2008

Rawan Alkurd, Raed M. Shubair and Ibrahim Abualhaol, "Survey on Device-to-Device Communications:Challenges and Design Issues," IEEE 12th International New Circuits and Systems Conference (NEWCAS), 2014.

Guopeng Zhang, Shuanshuan Wu, Lin Chen and Bo Dai, "Joint Relay Selection and Resource Allocation for D2D-enabled Cellular Communications," IEEE International Conference on Computer and Information Technology; Ubiquitous Computing and Communications; Dependable, Autonomic and Secure Computing; Pervasive Intelligence and Computing, 2015.

Rafay Iqbal Ansari, Syed Ali Hassan and Chrysostomos Chrysostomou, "Energy Efficient Relay Selection in Multi-hop D2D Networks," International Wireless Communications and Mobile Computing Conference (IWCMC), 2016.

Meng-meng Miao, and Jun Sun, Shi-xiang Shao, "A Cross-Layer Relay Selection Algorithm for D2D Communication System," International Conference on Wireless Communication and Sensor Network, pp.448-453, ,2014.

Xiran Ma, Rui Yin, Guanding Yu, and Zhaoyang Zhang, "A Distributed Relay Selection Method for Relay Assisted Deviceto-Device Communication System," IEEE 23rd International Symposium on Personal Indoor and Mobile Radio Communications (PIMRC), pp.1020-1024,Nov.2012.

Bighnaraj Panigrahi, Rashmi Ramamohan, Hemant Kumar Rath, and Anantha Simha, "Dynamic Relay Selection and Channel Adaptive Uplink For LTE Device-to-Device (D2D) Communication," IEEE 27th Annual IEEE International Symposium on Personal, Indoor and Mobile Radio Communications - (PIMRC): Mobile and Wireless Networks, 2016. 
K. Doppler, M. P. Rinne, P. Janis, C. Ribeiro, and K. Hugl, "Deviceto-device communications; functional prospects for LTEAdvanced networks,"in Proc. IEEE ICC Workshops, pp. 1-6, 2009.

K.Shamganth, Sami Al-Ghnimi and Martin J Sibley, "Performance analysis of threshold based relay selection in cooperative wireless networks," International Journal of Electronics and Communication Engineering \& Technology, vol.7, pp.115-124, Jan.2016.

N. Golrezaei, A. F. Molisch, and A. G. Dimakis, "Base-station assisted device-to-device communications for high-throughput wireless video networks," in Proc. IEEE ICC, pp. 7077-7081, 2012. 